\title{
Genotypic Variation for Resistance to Phytophthora cactorum in a California Strawberry Breeding Population
}

\author{
Douglas V. Shaw ${ }^{1}$ and John Hansen \\ Plant Sciences Department, One Shields Avenue, University of California, Davis, CA 95616 \\ Greg T. Browne \\ USDA, ARS, Crops Pathology and Genetics Research Unit, Department of Plant Pathology, University \\ of California, Davis, CA 95616
}

\begin{abstract}
ADDITIONAL INDEX WORDs. heritability, year $\times$ genotype interaction, runner plants
Aвstract. One hundred-eighty six strawberry genotypes from the Univ. of California strawberry (Fragaria $\times$ ananassa Duch.) breeding program were evaluated for resistance to Phytophthora cactorum Schroet. in trials conducted over 6 years; 60 of these genotypes were tested in 2 years or more. Mother plants of each genotype were grown in a propagation nursery beginning in June, and runner plants were set into soil infested with inoculum from a mix of four $P$. cactorum isolates in August or September of the same year. Runner plants of each genotype were harvested from the inoculated nursery, transferred to a fruiting field location, and evaluated for disease symptoms during the winter and spring following inoculation using a disease severity score. Significant variation for the disease severity score was detected due to years, genotypes, and their interaction. Differences among genotypes were responsible for $60.6 \%$ of the phenotypic variance, whereas years and year $\times$ genotype interactions contributed relatively little to this variance, $8.2 \%$ and $9.3 \%$, respectively. A separate analysis conducted using a balanced subset of six cultivars that were present in all trial years detected variance components due to years and year $\times$ genotype interaction slightly smaller than those estimated for the complete trial, $5.0 \%$ and $3.9 \%$, respectively. These results highlight the utility of the screening system and suggest that stable resistance to $P$. cactorum is obtainable in California strawberry breeding populations and production systems.
\end{abstract}

Strawberry is sensitive to crown rot caused by Phytophthora cactorum, and widespread infection with this pathogen can be a limiting factor to successful fruit production (Browne et al., 2002; Maas, 1984). Symptoms of this disease can vary from general plant stunting to collapse and mortality associated with necrosis in the plant crown, roots, and petioles. Infection of susceptible cultivars by $P$. cactorum in California production systems can reduce fruit yield for susceptible cultivars by $50 \%$ or more (Browne et al., 2002; Shaw and Larson, 2000). Cultivars differ substantially in their susceptibility to $P$. cactorum and breeding for resistance appears a likely contributor to an integrated system for managing this pathogen in commercial plantations.

Differences among cultivars for their resistance to P. cactorum has been the subject of multiple investigations (Browne et al., 1998; Parikka, 2003). Evaluations of genetic resistance to the pathogen in strawberry have used several artificial inoculation methods; field, greenhouse, and in vitro screening methods for resistance have been described (Bell et al., 1997; Browne et al., 1998; Eikemo et al., 2000). The results of these tests, especially those conducted in greenhouse or in vitro, have been variable, and the heterogeneity of results has been attributed to differences in test environments and to the physiological condition of the strawberry plants tested. In addition, differences in the aggressiveness of $P$. cactorum isolates have been demonstrated (Bhat et al., 2006; Eikemo et al., 2004). Whether differences in isolate aggressive-

Received for publication 21 Apr. 2006. Accepted for publication 23 June 2006. ${ }^{1}$ Corresponding author. E-mail: dvshaw@ ucdavis.edu; phone: (530) 752-0905; FAX: (530) 752-8502. ness imply race-specific interactions with different strawberry genotypes is not known. However, genotype $\times$ isolate specificity of resistance response has been demonstrated for strawberry with Phytophthora fragariae Hickman var. fragariae, which exists in several races that are distinguished by the responses of different cultivars (Maas et al., 1989; Van de Weg, 1997).

In California, soilborne pathogens in the strawberry fruiting field usually are controlled with pre-plant soil fumigation, but eradication of Phytophthora de Bary species at all depths in field soil is seldom if ever achieved. Furthermore, Phytophthora species can enter the production system through irrigation water either in the fruiting field or propagation nursery systems (Gordon et al., 2002; Wilhelm and Paulus, 1980) and reproduce rapidly under disease-conducive conditions. Phytophthora cactorum is the most common Phytophthora species identified in California strawberry nurseries and fruiting fields (Browne et al., 1998), and infection patterns suggest that disease observed in the fruiting field usually originates from infection that took place in the propagation nursery.

The objective of the experiment reported below was to evaluate the genotypic variation for resistance to $P$. cactorum in the Univ. of California (UC) strawberry breeding population using a system that mimics the infection pathway expected to be of most consequence in California production systems (i.e., infection at the nursery and transfer of infected plants to fruiting fields). This system includes several stages at which the propagation environment for plants and disease can vary over years. Thus a second important goal of this study was to evaluate the stability of genotypic resistance responses over years and to obtain a preliminary estimate of the cumulative magnitude of variation that can be expected due to environmental and inoculum sources. 


\section{Materials and Methods}

Resistance evaluations were conducted over a 6-year period beginning in 2000. Each annual trial consisted of two stages: 1) a nursery propagation and inoculation step, and 2) an evaluation of disease symptoms after transplanting of infected runner plants to a fruiting field environment.

Thirty-nine to 59 genotypes were included in each annual trial and 186 unique genotypes were tested over the 6-year period. Sixty of the 186 genotypes were evaluated in 2 years or more. The genotypes included in these trials were advanced selections or cultivars from the UC strawberry breeding program, and this sample included nearly all of the parents used in crosses conducted by this program from 1999 to 2005 . None of these genotypes had been tested for resistance to $P$. cactorum prior to the present trials, so the genotypic variation in this sample should provide an accurate representation of the range of genetic resistance currently available in this breeding population.

Inoculum was prepared following Wilcox and Mircetich (1985). Four isolates of P. cactorum obtained from symptomatic strawberry plants found in commercial fields in California were used to produce the inoculum each year, and the inoculum applied to each nursery plot contained equal fractions of the material produced from these four isolates. Two of the four isolates were replaced each year in an effort to adequately represent the pathogen population and to avoid the risk of change in aggressiveness that can result from repeated propagation of the pathogen in culture (Erwin, 1983). As a consequence, trials separated by 2 years contained inoculum produced from unique sets of isolates.

Inoculation of all genotypes was performed in a propagation nursery located near Winters, Calif. (lat. $38^{\circ} 30^{`} \mathrm{~N}$, long. $121^{\circ} 59^{\prime} \mathrm{W}$ ). An infection nursery was established by planting two or three cold-stored plants of each genotype in early June of the inoculation year. The nursery was established in soil previously fumigated with 2 methyl bromide : 1 trichloronitromethane (chloropicrin) at $392 \mathrm{~kg} \cdot \mathrm{ha}^{-1}$. Runner plants produced in the nursery prior to inoculation were set into the mother plant rows and were not used for later testing. Approximately $0.5 \mathrm{~m}^{2}$ of soil adjacent to each nursery mother plant was cultivated and $100 \mathrm{~mL}$ of inoculum per mother plant was incorporated into this prepared soil; soil inoculation dates ranged from 1 Aug. to 9 Sept. for the 6 years. Runner plants that rooted after the inoculation date were then set in the infested soil and grown until fully developed.

Twelve runner plants of each genotype were harvested from the inoculated nursery and transplanted to a location near Watsonville, Calif. (lat. $36^{\circ} 54^{`} \mathrm{~N}$, long. $121^{\circ} 48^{\prime} \mathrm{W}$ ). Nursery harvest dates were 28 Oct. to 14 Nov. for the 6 years, and runner plants were planted in fruiting field trials after 3 to $7 \mathrm{~d}$ in cold storage at $2{ }^{\circ} \mathrm{C}$. Two replicates, each containing six plants from the inoculated nursery, were established on commercial strawberry beds (two-row raised beds with $1.32-\mathrm{m}$ centers and $0.36-\mathrm{m}$ in-row plant spacing) in a randomized complete-block design and treated using standard cultural practices (Welch, 1989). In addition, two runner plants for each genotype from a noninoculated nursery at the Winters location were harvested and transplanted to the fruiting-field trial on the same dates to serve as a control; noninfected control plants were planted adjacent to each inoculated plot but were separated in the fruiting field trial by $0.72 \mathrm{~m}$ from the nearest inoculated plant. Runner plants from inoculated nursery plots were symptomless prior to harvest from the propagation nursery, although disease symptoms were occasionally observed on their mother plants. At the time of their harvest from the propagation nursery, some runner plants from inoculated nursery plots contained roots with a darkened cortex, although plants from the noninoculated plots occasionally exhibited some root discoloration as well, and this characteristic may not be a symptom of $P$. cactorum infection.

Disease symptoms were first observed on the plants from infested nursery plots in Watsonville during late December or early January of each evaluation year. A disease severity score was recorded for individual plots in the Watsonville trial on three to five dates in each year, beginning when symptoms were observed in the most susceptible genotypes and continuing at 3to 4-week intervals until no change in symptoms was observed. The severity score was recorded for each date on a scale of 1 to 5 , where $1=$ severely diseased and $5=$ no symptoms of disease (i.e., comparable in appearance to the noninoculated controls from the same genotype). A combined severity score was generated for each plot as the arithmetic mean of scores for all evaluation dates (Shaw et al., 1996). The percentage of plants per plot with severe stunting symptoms also was recorded, but preliminary analyses showed this variable to be strongly associated with the disease severity score $(r=-0.92)$ and values obtained for this variable were not analyzed further.

Analysis of variance (ANOVA) was conducted for disease severity scores with years, replications in years, genotypes, and their interactions treated as random effects. All analyses were performed using SAS procedure GLM (release 8; SAS Institute, Cary, N.C.), with expected mean squares and synthetic F ratios for individual sources calculated using the RANDOM and TEST options of this procedure. The importance of all sources of variation was further resolved by obtaining estimates of variance components using the restricted maximum likelihood (REML) option of SAS procedure VARCOMP. The relative magnitudes of variance components were assessed through their contribution to the phenotypic variance and summarized by calculating a broad-sense heritability as:

$$
\mathrm{H}^{2}=\sigma_{\mathrm{G}}^{2} /\left(\sigma_{\mathrm{G}}^{2}+\sigma_{\mathrm{Y} \times \mathrm{G}}^{2}+\sigma_{\mathrm{E}}^{2}\right),
$$

where $\sigma_{G}^{2}$ is the variance among genotypes, $\sigma_{Y \times G}^{2}$ is the variance due to year $\times$ genotype interaction, and $\sigma_{\mathrm{E}}^{2}$ is the error variance.

Most of the genotypes evaluated in multiple years were tested in two sequential annual trials; consequently their inoculum included shared isolates. One caution here is that, together with the genotypic imbalance over years, this design will underestimate any contribution to year $\times$ genotype interaction variances that might result from true genetic $\times$ isolate interaction. To further resolve the consistency of resistance response over unique sets of isolates, disease scores for a subset of six cultivars ('Albion', 'Aromas', 'Camarosa', 'Camino Real', 'Diamante', 'Ventana') that were included in all six annual trials were analyzed separately.

\section{Results and Discussion}

Mean disease severity scores for individual genotypes were distributed approximately as a normal curve (Fig. 1). This distribution provided no evidence of modality that might indicate the presence of a major gene for resistance, such as that described for P. fragariae var. fragariae in some strawberry populations (Van de Weg, 1997). The most susceptible genotypes in this strawberry population had severity scores below 2.0 and near $100 \%$ stunting or collapse, whereas a substantial fraction, 49 of 186, had scores $>4.0$ and would be rated as highly resistant. Some of the variation 


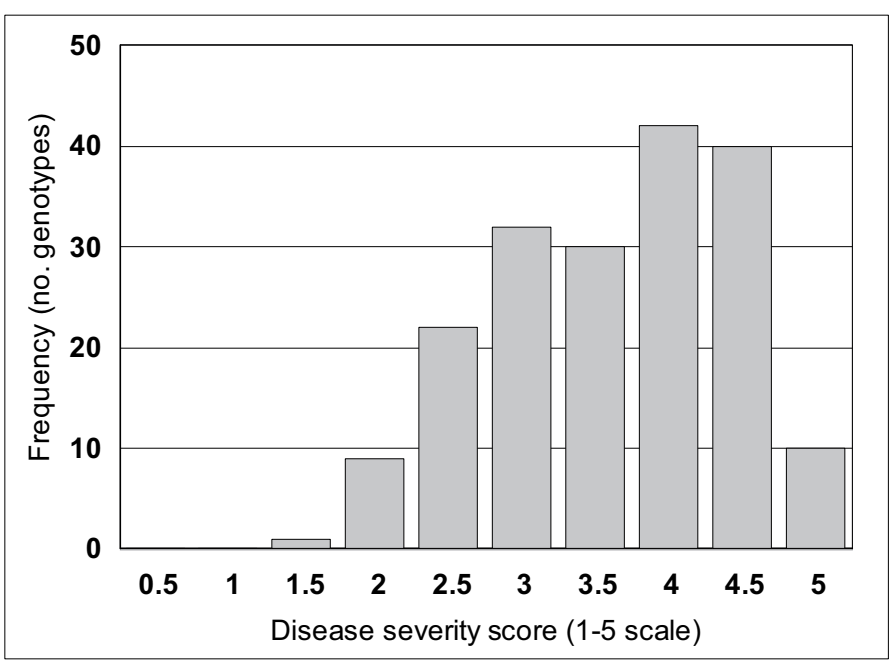

Fig. 1. Distribution of mean disease severity scores from 186 strawberry genotypes evaluated for resistance to Phytophthora cactorum over a 6-year period. The severity score was calculated as the arithmetic mean of observations collected on three to five dates per year, using a scale of 1 to 5 , where $1=$ severely diseased and $5=$ no symptoms of disease (i.e., comparable in appearance to the noninoculated controls from the same genotype).

observed in severity scores may be due to differences among the sets of genotypes tested in different years (Table 1). However, $t$ tests conducted for each individual year detected no difference in severity scores calculated using the entire set of genotypes vs. the balanced subset of cultivars, suggesting that any variation detected due to years is likely attributable to environmental effects rather than genetic sampling.

Descriptive statistics for the disease severity scores of the six cultivars tested in all years are given in Table 2 . The severity scores for these genotypes were distributed somewhat uniformly over the range of values detected for the entire population. Seven of the genotypes from the entire population had scores that suggest greater resistance than any of the six cultivars, and 12 genotypes were more susceptible, although the experimental design used here is not precise enough to verify that these differences were statistically significant.

Statistically significant $(P<0.05)$ or highly significant $(P<$ $0.01)$ variances were detected for the disease severity scores due to all genetic and environmental sources from ANOVA of the entire population (Table 3 ). Genotypic variance, which reflects differences for disease response that were stable across years, explained the largest fraction of the phenotypic variation $(60.4 \%)$, whereas the fraction of the phenotypic variance explained by year $\times$ genotype interaction was small (9.8\%). Similarly, the broad-sense heritability $\left(\mathrm{H}^{2}=0.66\right)$ suggests that the majority of the variation relevant to selection response for $P$. cactorum resistance is attributable to differences among genotypes that are stable over years.

ANOVA of disease severity scores for the balanced subset of six cultivars present in all trials detected statistically significant variance only due to years and genotypes, although the magnitude and distribution of variance components estimated for this subset was similar to that obtained for the entire population (Table 3). The differences in statistical significance observed here may be attributed mainly to differences in experiment size and power. Both the fraction of the phenotypic variance explained by differences among genotypes and the broad-sense heritability were larger for the subset analysis; these estimates are probably inflated somewhat in the subset sample by the use of uniformly distributed geno-
Table 1. Average disease severity score for 186 strawberry genotypes inoculated with Phytophthora cactorum over a 6-year period and for a balanced subset of six cultivars evaluated in all 6 years.

\begin{tabular}{lccc}
\hline & & \multicolumn{2}{c}{$\begin{array}{c}\text { Disease severity score } \pm \text { SE } \\
(1-5 \text { scale })^{z}\end{array}$} \\
\cline { 3 - 4 } Trial year & $\begin{array}{c}\text { Genotypes tested } \\
\text { (no.) }\end{array}$ & $\begin{array}{c}\text { All } \\
\text { genotypes }\end{array}$ & $\begin{array}{c}\text { Balanced } \\
\text { subset }\end{array}$ \\
\hline $2000-1$ & 40 & $3.89 \pm 0.09$ & $3.96 \pm 0.26$ \\
$2001-2$ & 39 & $3.55 \pm 0.09$ & $3.88 \pm 0.29$ \\
$2002-3$ & 40 & $3.69 \pm 0.10$ & $3.67 \pm 0.25$ \\
$2003-4$ & 39 & $3.17 \pm 0.10$ & $3.25 \pm 0.22$ \\
$2004-5$ & 59 & $3.47 \pm 0.08$ & $3.65 \pm 0.29$ \\
$2005-6$ & 59 & $3.16 \pm 0.09$ & $3.36 \pm 0.40$
\end{tabular}

${ }^{2}$ The severity score was calculated as the arithmetic mean of observations collected on three to five dates per year, using a scale of 1 to 5 , where 1 $=$ severely diseased and $5=$ no symptoms of disease (i.e., comparable in appearance to the noninoculated controls from the same genotype).

Table 2. Disease severity score for six strawberry cultivars inoculated with Phytophthora cactorum and evaluated in six annual trials.

\begin{tabular}{lc}
\hline Cultivar & $\begin{array}{c}\text { Disease severity } \\
\text { score } \pm \mathrm{SE} \\
(1-5 \text { scale })^{\mathrm{z}}\end{array}$ \\
\hline Albion & $4.51 \pm 0.13$ \\
Aromas & $4.04 \pm 0.17$ \\
Camarosa & $3.68 \pm 0.11$ \\
Camino Real & $4.55 \pm 0.13$ \\
Diamante & $2.15 \pm 0.16$ \\
Ventana & $2.85 \pm 0.17$ \\
\hline
\end{tabular}

$\overline{\text { The severity score was calculated as the arithmetic }}$ mean of observations collected on three to five dates per year, using a scale of 1 to 5 , where $1=$ severely diseased and $5=$ no symptoms of disease (i.e., comparable in appearance to the noninoculated controls from the same genotype).

Table 3. ANOVA results and variance component analysis of disease severity score for 186 strawberry genotypes inoculated with Phytophthora cactorum over a 6-year period and for a subset of six cultivars evaluated in all 6 years.

\begin{tabular}{|c|c|c|c|c|}
\hline \multirow[b]{3}{*}{ Source } & \multicolumn{4}{|c|}{ Disease severity scorez } \\
\hline & \multicolumn{2}{|c|}{ All genotypes } & \multicolumn{2}{|c|}{ Balanced subset } \\
\hline & $\mathrm{df}$ & Mean squares & $\overline{\mathrm{df}}$ & Mean squares \\
\hline$\overline{\text { Year }(Y)}$ & 5 & $2.34^{* *}$ & 5 & $0.94^{*}$ \\
\hline Replication/year & 6 & 0.32 & 6 & 0.16 \\
\hline Genotype (G) & 185 & $1.77^{* *}$ & 5 & $11.05^{* *}$ \\
\hline $\mathrm{Y} \times \mathrm{G}$ & 85 & $0.31^{\text {** }}$ & 25 & 0.25 \\
\hline Error & 270 & 0.16 & 30 & 0.16 \\
\hline$\sigma_{Y}^{2}{ }_{Y}$ & & $0.063(8.2 \%)$ & & $0.058(5.0 \%)$ \\
\hline$\sigma_{R / Y}^{2}$ & & $0.004(0.5 \%)$ & & $0.000(0.0 \%)$ \\
\hline$\sigma_{\mathrm{G}}^{2}$ & & $0.465(60.6 \%)$ & & $0.900(77.1 \%)$ \\
\hline$\sigma_{Y \times G}^{2}$ & & $0.071(9.3 \%)$ & & $0.045(3.9 \%)$ \\
\hline$\sigma_{\mathrm{E}}^{2}$ & & $0.164(21.4 \%)$ & & $0.164(14.0 \%)$ \\
\hline $\mathrm{H}^{2}$ & & 0.66 & & 0.81 \\
\hline
\end{tabular}

${ }^{2}$ The severity score was calculated as the arithmetic mean of observations collected on three to five dates per year, using a scale of 1 to 5 , where 1 $=$ severely diseased and $5=$ no symptoms of disease (i.e., comparable in appearance to the noninoculated controls from the same genotype).

Variance components with the percentage of the phenotypic variance in parentheses. 
types rather than the random sample represented in the combined population analysis (Searle et al., 1992). The variance estimated for year $\times$ genotype interaction for this supplemental analysis was substantially smaller than that for the combined population analysis when considered as a percentage, but was similar across samples in absolute value $\left(\sigma_{\mathrm{Y} \times \mathrm{G}}^{2}=0.071\right.$ vs. 0.045 , Table 3$)$. Year $\times$ genotypic interaction variances reflect the failure of individual genotypes to respond consistently over several potential yearly environments, including annual differences in infection nursery conditions and fruiting field environment, and in this study will also reflect any inconsistency in resistance response due to specific host genotype-isolate reactions. The absence of an increase in $\sigma^{2}{ }_{Y \times G}$ for the supplemental analysis, where all genotypes were tested over a broader range of isolates, suggests that isolate-specific interactions contributed little to the phenotypic variance for resistance traits, and will not be an obstacle to improving resistance to $P$. cactorum in strawberry.

Taken together, our results suggest substantial opportunity for developing strawberry cultivars that are highly resistant $P$. cactorum in California production systems. The screening system employed for our analysis is expected to mimic the actual path of infection expected in commercial systems, so the range of variation we observed should predict that for commercial systems with considerable accuracy. The precision of selection for resistance based on the nursery infection screening procedure could be improved either by testing genotypes in multiple years or by increasing the number of replicates in each year. Because the error variance component within years is estimated as over twice the magnitude of the year $\times$ genotype interaction variance, an argument based on selection efficiency would increase replications within years rather than the number of evaluation seasons (Hansche, 1983). The range and stability of variation detected in the genotypes evaluated in our study is especially promising, as these genotypes represent the parents used in the UC cultivar development program. Ultimately, selection response for resistance to $P$. cactorum in the offspring of these genotypes will depend on the distribution of genotypic variance among additive and nonadditive sources, which could not be evaluated here.

\section{Literature Cited}

Bell, J.A., D.W. Simpson, and D.C. Harris. 1997. Development of a method for screening strawberry germplasm for resistance to Phytophthora cactorum. Acta Hort. 439:175-179.

Bhat, R.G., P.M. Colowit, T.H. Tai, M.K. Aradhya, and G.T. Browne. 2006. Genetic and pathogenic variability in Phytophthora cactorum affecting fruit and nut crops in California. Plant Dis. 90:161-169.
Browne, G.T., H.E. Becherer, S.T. McLaughlin, and R.J. Wakeman. 2002. Strategies for management of Phytophthora on California strawberries. The Pink Sheet: California Strawberry Commission Strawberry News Bul. 02-09.

Browne, G.T., M.R. Vazquez, R.J. Wakeman, and H.E. Becherer. 1998. Screening procedures and cultivar evaluations for resistance to Phytophthora. The Pink Sheet: California Strawberry Commission Strawberry News Bul. 98-29.

Eikemo, H, S.S. Klemsdal, I. Riisberg, P. Bonants, A. Stensvand, and A.M. Tronsmo. 2004. Genetic variation between Phytophthora cactorum isolates differing in their ability to cause crown rot in strawberry. Mycol. Res. 108:317-324.

Eikemo, H., A. Stensvand, and A.M. Tronsmo. 2000. Evaluation of methods for screening strawberry cultivars for resistance to crown rot caused by Phytophthora cactorum. Ann. Appl. Biol. 137:237-244.

Erwin, D.C. 1983. Variability within and among species of Phytophthora, p. 149-165. In: D.C. Erwin, S. Bartnicki-Garcia, and P.H. Tsao (eds.). The international symposium on Phytophthora: Its biology, taxonomy, ecology, and pathology. APS Press, St. Paul, Minn.

Gordon, T.R., S.C. Kirkpartick, D.V. Shaw, and K.D. Larson. 2002. Differential infection of runner plant generations by Verticillium dahliae in a high elevation strawberry (Fragaria $\times$ ananassa Duch.) nursery. HortScience 37:932-935.

Hansche, P.E. 1983. Response to selection, p 154-171. In: J.N. Moore and J. Janick (eds.). Methods in fruit breeding. Purdue University Press, West Layfayette, Ind.

Maas, J.L. 1984. Compendium of strawberry diseases. APS Press, St. Paul, Minn.

Maas, J.L., G.J. Galletta, andA.D. Draper. 1989. Resistance in strawberry to races of Phytophthora fragaria and to isolates of Verticillium from North America. Acta Hort. 265:521-526.

Parikka, P. 2003. Susceptibility of strawberry varieties to crown rot (Phytophthora cactorum) in greenhouse tests. Acta Hort. 626:183-189.

Searle, S.R., G. Casella, and C.E. McCulloch. 1992. Variance components. Wiley, New York.

Shaw, D.V., W.D. Gubler, K.D. Larson, and J. Hansen. 1996. Genetic variation for field resistance to Verticillium dahliae evaluated using genotypes and segregating progenies of California strawberries. J. Amer. Soc. Hort. Sci. 121:625-628.

Shaw, D.V. and K.D. Larson. 2000. Control of Phytophthora cactorum in Diamante plantings using pre-plant dips with Aliette. The Pink Sheet: California Strawberry Commission Strawberry News Bul. 00-08.

Van de Weg, W.E. 1997. Resistance to Phytophthora fragaria var. fragaria in strawberry: The Rfp2 gene. Theor. Appl. Genet. 94:1092-1096.

Welch, N. 1989. Strawberry production in California. University of California, Coop. Ext. Lflt. 2959.

Wilcox, W.F. and S.M. Mircetich. 1985. Pathogenicity and relative virulence of seven Phytophthora spp. on Mahaleb and Mazzard cherry. Phytopathology 75:221-226.

Wilhelm, S. and A.O. Paulus. 1980. How soil fumigation benefits the California strawberry industry. Plant Dis. 64:264-270. 